\title{
Consumptive and non-consumptive effects of predators vary with the ontogeny of their prey
}

\author{
Albert Pessarrodona, ${ }^{1,5,6}$ Jordi Boada, ${ }^{1,2}$ Jordi F. Pagès, ${ }^{3}$ Rohan Arthur, ${ }^{1,4}$ and Teresa Alcoverro ${ }^{1,4}$ \\ ${ }^{1}$ Centre d'Estudis Avançats de Blanes (CEAB-CSIC), Carrer d'Accés a la cala Sant Francesc 14, Blanes 17300 Spain \\ ${ }^{2}$ Centre for Marine Bio-Innovation, School of Biological, Earth, and Environmental Sciences, University of New South Wales, Sydney, \\ New South Wales 2052 Australia \\ ${ }^{3}$ School of Ocean Sciences, Bangor University, Menai Bridge LL59 5 AB United Kingdom \\ ${ }^{4}$ Nature Conservation Foundation, Amritha, 1311, 12th Cross, Vijayanagara 1st stage, Mysore 570017 India
}

Citation: Pessarrodona, A., J. Boada, J. F. Pagès, R. Arthur, and T. Alcoverro. 2019. Consumptive and non-consumptive effects of predators vary with the ontogeny of their prey. Ecology 00 (00):e02649. 10.1002/ecy.2649

Abstract. Predators exert a strong influence on ecological communities by reducing the abundance of prey (consumptive effects) and shaping their foraging behavior (non-consumptive effects). Although the prevalence of trophic cascades triggered by non-consumptive effects is increasingly recognized in a wide range of ecosystems, how its relative strength changes as prey individuals grow in size along various life stages remains poorly resolved. We investigated how the effects of predators vary with the ontogeny of a key herbivorous sea urchin, which is responsible for transforming diverse macroalgal forests to a barren state dominated by bare rock and encrusting coralline algae. We conducted a series of field and laboratory experiments to determine how susceptibility to predation, prey behavioral responses, and grazing impact on algal cover vary with sea urchin size. The consumptive effects of predators were greater on smaller sea urchin size classes, which were more susceptible to predation. Unexpectedly however, predator non-consumptive effects acted only on larger sea urchins, significantly reducing their grazing activity in the presence of predator cues. Crucially, only these larger sea urchins were capable of overgrazing macroalgae in the field, with non-consumptive effects reducing sea urchin foraging activity and macroalgal grazing impact by $60 \%$. The decoupling between risk and fear as prey grow indicates that the strength of consumptive and non-consumptive trophic cascades may act differently at different ontogenetic stages of prey. While the consumptive effects of predators directly influence population numbers, the consequences of non-consumptive effects may far outlive consumptive effects as prey grow, finding refuge in size, but not from fear.

Key words: fear; Mediterranean Sea; Paracentrotus lividus; regime shift; temperate reefs; top-down control; trait-mediated indirect interaction.

\section{INTRODUCTION}

The pervasive influence of predators on ecosystems has been extensively documented in terrestrial and marine environments (Shurin et al. 2002). Predators can indirectly regulate primary producers by consuming herbivores, as evidenced by density-mediated trophic cascades, in which the removal of top predators triggers population explosions of herbivorous prey, whose feeding can quickly overgraze vegetation (Estes et al. 2014, Ling et al. 2015). Additionally, the mere presence of predators can induce a host of non-consumptive effects on prey such as risk avoidance behaviors or the

Manuscript received 12 February 2018; revised 1 December 2018; accepted 14 January 2019. Corresponding Editor: Mark Carr.

${ }^{5}$ Present address: UWA Oceans Institute and School of Biological Sciences, University of Western Australia, Crawley, Western Australia 6009 Australia

${ }^{6}$ E-mail: pessa3@gmail.com production of defenses, thus adding to the total predator effects on prey populations (Schmitz et al. 1997, Peacor and Werner 2001, Trussell et al. 2006). In turn, these prey behavioral decisions may have implications for other species in the food web, resulting in behaviorally mediated trophic cascades, which can eventually influence ecosystem function (Suraci et al. 2016, Rasher et al. 2017, Haggerty et al. 2018). For instance, the presence of predators can indirectly affect primary producers by altering when, where, what, and how herbivores forage (Werner et al. 1983, Lima and Valone 1986, Wirsing et al. 2007), which can then affect vegetation-driven ecosystem functions such primary productivity or carbon capture storage (Schmitz et al. 2008, Burkholder et al. 2013, Atwood et al. 2015). Although both predator consumptive and non-consumptive effects can cascade down to influence primary producers, prey's interactions with their predators (and resources) are highly dynamic (Trussell et al. 2006, Preisser and Orrock 2012, Catano et al. 2016). Unpacking how the nature 
and strength of such interactions varies across ecological contexts, e.g., between species, across spatial scales, and over an individual's life, is critical to better understand how predators shape the structure and function of ecological communities.

An organism's body size is a fundamental trait influencing the strength of its trophic interactions in ecological networks (Werner and Gilliam 1984, Krenek and Rudolf 2014). Size strongly influences the energy intake requirements of an individual (Hemmingsen 1960), and often determines its vulnerability to predation (Preisser and Orrock 2012, Krenek and Rudolf 2014). As such, body size largely determines the relative costs of avoiding or accepting a certain degree of predation risk (the starvation-predation trade-off; McNamara and Houston 1987), and shapes the decisions prey must make to meet their energetic demands while avoiding their predators (Orrock et al. 2013). For instance, prey often decrease their foraging activity and take refuge in shelters upon detecting their predators, although these decisions are affected by their energy reserves and size (Vadas et al. 1994). Given that individuals usually change size with ontogeny, there should be a large selective pressure for prey to adjust their responses to the relative size-specific predation risk they are exposed to. As a result, many species undergo shifts in food and habitat use with ontogeny, creating complex, size-specific interactions with their predators and resources (Werner and Gilliam 1984). These size-specific responses are known to have important implications for trophic interactions and population dynamics (Werner et al. 1983, Eklöv and Werner 2000). However, how ontogenetic changes in prey size influence the strength of trophic cascades by modulating the direction of predator consumptive and non-consumptive effects remains poorly understood.

In temperate reefs worldwide, sea urchins are important prey, playing a key role in the transmission of topdown effects (Filbee-Dexter and Scheibling 2014, Ling et al. 2015, Carr and Reed 2016). Unchecked by predators, they can completely denude macroalgal forests, driving a shift from complex, diverse algal assemblages to barrens: homogenous, functionally impoverished systems dominated by bare rock and encrusting coralline algae (Harrold and Reed 1985, Estes and Duggins 1995, Pinnegar et al. 2000). The formation and persistence of barren areas has traditionally been linked to changes in sea urchin abundance, either as a result of the loss of their predators by overharvesting (Estes and Duggins 1995, Sala et al. 1998, Shears and Babcock 2003), enhanced urchin recruitment (Cardona et al. 2013) or both (Ling et al. 2009). The presence of predators however also induces a host of non-consumptive effects on sea urchins, including habitat shifts, reductions in grazing activity and movement patterns (Nelson and Vance 1979, Cowen 1983, Scheibling and Hamm 1991, Freeman 2006, Pagès 2013). For example, sea urchins increase refuge (e.g., crevice) occupancy, move less and have shorter home range sizes in areas where predators abound (Hereu 2005, Spyksma et al. 2017). Reductions in sea urchin activity in response to predators often translate to decreases in feeding rates (McKay and Heck 2008, Matassa 2010) and results from trials and experimental mesocosms suggest that these non-consumptive predator effects may have implications for algal abundance (Byrnes et al. 2006, Freeman 2006).

While the possibility of non-consumptive predator effects in macroalgal forest ecosystems is well established, determining how relevant they are in the field is much more complex. Controlled laboratory studies are compelling, but they may overestimate the importance of non-consumptive effects by artificially enhancing the detection threshold of predator chemical cues (Harding and Scheibling 2015, Peers et al. 2018). Achieving a more nuanced understanding of the dynamics of predator effects in complex natural settings requires integrating how their strength varies across space and gradients of habitat complexity (Catano et al. 2016), or along the size spectrum of predators and prey for example. Overall, arriving at a more honest appraisal of the relative strength of consumptive and non-consumptive predator effects needs multiple lines of evidence, combining controlled laboratory and field experiments with more descriptive observational approaches in field settings (Haggerty et al. 2018).

Here, we use macroalgal forest ecosystems subject to strong top-down control in the Mediterranean Sea to investigate how prey size mediates ecological interactions, and to investigate its implications for ecosystem structure. We used a combination of field and laboratory experiments to determine whether the size of a key herbivorous sea urchin affected its susceptibility to predation (consumptive effects), behavioral responses (nonconsumptive effects) and its grazing impact on macroalgal ecosystems.

\section{Methods}

\section{Study system and study design}

Our investigations were conducted in the shallow temperate rocky reefs of the northwest Mediterranean Sea (4-12 $\mathrm{m}$ depth), which are dominated by a diverse assemblage of photophilic macroalgae subject to strong top-down control (Pinnegar et al. 2000, Hereu et al. 2008). The sea urchin Paracentrotus lividus is the principal benthic herbivore in this system, and mediates the transition from macroalgal forests to barren areas across the Mediterranean (Verlaque 1984, Sala et al. 1998). P. lividus has two distinct guilds of predators: several species of omnivorous fish - the most important being Diplodus sargus, which typically accounts for $>50 \%$ of total sea urchin predation - and various benthic predators, which include the sea snail Hexaplex trunculus and the sea star Marthasterias glacialis (Sala and Zabala 1996, Boada et al. 2015). Predators are known to induce strong behavioral responses in $P$. lividus, such as changes 
in movement patterns (Hereu 2005, Pagès 2013) and habitat use (Verlaque 1984, Sala and Zabala 1996). We employed a triangulation of approaches (multiple lines of evidence, sensu Patton 1999) combining field comparisons, field experiments, and controlled laboratory assays to determine the importance of predator consumptive effects on different sea urchin size classes (Fig. 1a); the size-specific effect of sea urchin grazing on the algal assemblage (Fig. 1b); the significance of predator non-consumptive effects on size-specific sea urchin grazing (Fig. 1c); and the overall influence of indirect consumptive and non-consumptive effects for algal assemblages (Fig. 1d).

\section{Size-mediated predator consumptive effects}

To establish how prey size mediates predator consumptive effects on prey populations (Fig. 1a), we exposed tethered $P$. lividus individuals from a wide range

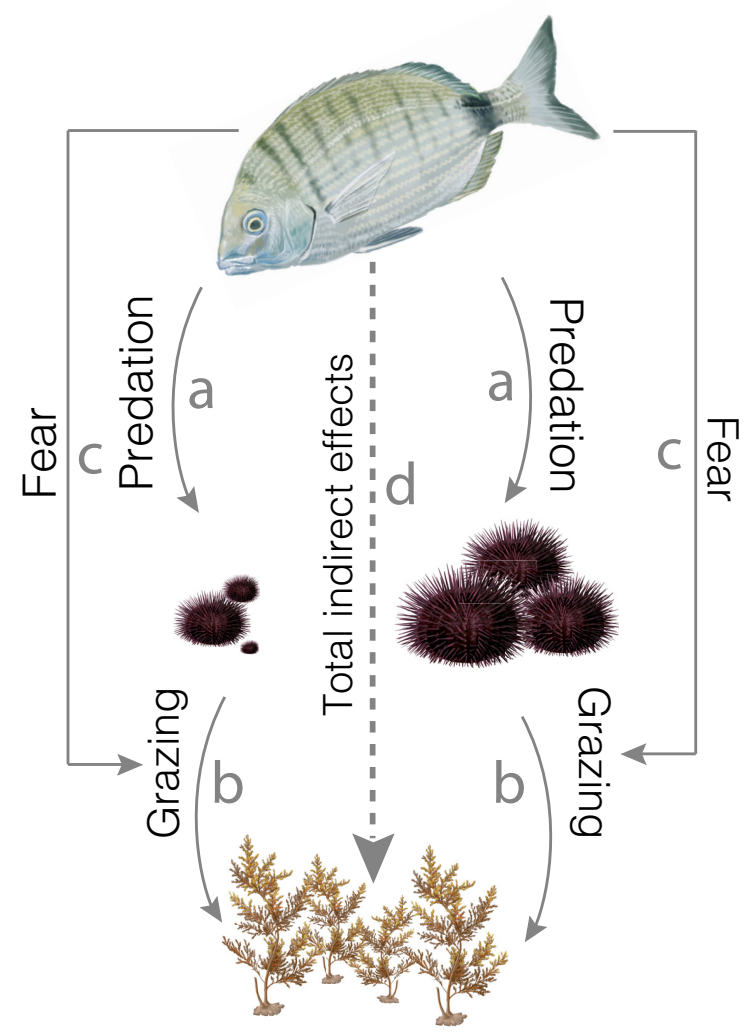

FIG. 1. Schematic representation of the ecological interactions examined in this study. A guild of predators (represented here by the dominant predator Diplodus sargus) controls the populations of the key herbivorous sea urchin Paracentrotus lividus via predation (a). Paracentrotus lividus mediates the transition from algal forests to barren areas via size-dependent grazing (b). Fear of predators may impact the activity levels of different urchin size classes and their grazing impact (c). Predators thus have size-mediated consumptive and non-consumptive indirect effects on algal assemblages (d). of sizes to two different predation risk scenarios: a high predation risk treatment (hereafter high-risk) in a marine reserve that has high abundances of fish predators, and a low predation risk treatment (hereafter low-risk), in two nearby fished areas with low predator abundance (see Appendix S1: Fig. S1 for a map of the study area). Our high-risk assays were performed in the Medes Islands Marine Reserve, a group of seven limestone islets located $1 \mathrm{~km}$ offshore L'Estartit $\left(42^{\circ} 02^{\prime} 47^{\prime \prime} \mathrm{N}, 03^{\circ} 13^{\prime} 11^{\prime \prime}\right.$ E). Fish biomass inside this no-take marine reserve has seen a remarkable recovery since fishing was prohibited in 1983 (García-Rubies et al. 2013), and is now among the highest in the Mediterranean (Guidetti et al. 2014). Our low-risk assays were conducted at two separate sites in the neighboring Montgrí coast, which has a similar habitat structure, but where recreational and artisanal fishing are permitted with some restrictions (Montgrí Medes Islands and Baix Ter Natural Park 2010). Geologically, the Montgrí Massif and the Medes islands are morphologically continuous (Llompart and Pallí 1984), with both locations characterized by a limestone seascape with abundant crevices, underwater tunnels, and caves (see habitat cartography in Hereu et al. 2012). At the time of sampling, fish assemblages along the Montgrí coast were similar to most overfished coastal areas across the northwest Mediterranean, with most predatory species present at very low abundances and restricted to small sizes (Sala and Zabala 1996, Hereu 2004, Sala et al. 2012). We selected two different sites along the Montgrí coast to account for potential spatial variability in predation outside the low-risk area.

At each of our study sites, 40 sea urchins ranging from 1.7 to $6.4 \mathrm{~cm}$ test diameter were tethered by piercing their tests from the oral to the aboral region and passing a thin monofilament line through the skeleton. The lines were then individually attached to a $1 \mathrm{~kg}$ weight, restricting the sea urchin's ability to move and find shelters to within $10-20 \mathrm{~cm}$ of the weight. The tethers were randomly deployed several meters apart from each other over a vast area $\left(\sim 300 \mathrm{~m}^{2}\right)$ on exposed surfaces of a macroalgae-dominated rocky reef at $5 \mathrm{~m}$ depth (see Boada et al. [2015b] for details). The area over which the sea urchins were deployed was relatively uniform, and all tethered urchins had a similar probability of finding refugia within the tethered range. After $24 \mathrm{~h}$, we retrieved the tethers and recorded the percentage of eaten sea urchins in each $1-\mathrm{cm}$ size class.

To evaluate how the susceptibility of sea urchins to predation varies with urchin size, we used a generalized linear mixed-effects model with alive/dead as a binomial response variable and risk (high and low risk), site, and sea urchin size as categorical and continuous predictor variables respectively ( $n=40$ per site). Site was included as a random effect nested within the risk factor. We treated sea urchin size as a continuous variable - rather than categorizing urchins in discrete size classes - as some sizes were more difficult to find than others, and the replicate 
numbers of urchins in some size classes would have been much lower than desirable for statistical power.

All the statistical analyses were conducted using the R environment (R Development Core Team 2016). For this and each of the linear models used throughout our analysis, we tested for normality and homoscedasticity of the residuals using Shapiro-Wilk and Bartlett tests as well as visually inspecting residuals vs. fitted values and quantile-quantile plots. Whenever the residual plots indicated heteroscedasticity, the variance structure was modeled using the weights argument in the lme function. The best variance structure was determined by comparing Akaike's Information Criterion (AIC) and standardized residual plots (Zuur et al. 2011). We also considered $\log$ and square-root transformations to improve residual plots. Once the best variance structure was determined, models were simplified using step-wise selection based on AIC. We always started from a full model (i.e., all factors and interactions) and the process involved sequentially dropping a given term from the model until a minimum AIC was achieved (Zuur et al. 2011; see Table 1 for final models).

To show how predation susceptibility varied at each of our risk treatments, we plotted the model predictions for size-predation relationships for each of our risk scenarios, respectively, using the visreg function in the visreg package (Breheny and Burchett 2017). The function visreg allowed us to visualize the relationship between the predicted outcome and our explanatory variable while holding other variables constant.

\section{Size-specific sea urchin grazing on algal assemblages}

We established the relationship between sea urchin size and grazing impact on algal cover (Fig. 1b) in the high-risk field site (Medes Islands Marine Reserve). The grazing impact of sea urchins residing in small rock depressions, crevices, and holes can be clearly noticed as their feeding activity leaves a distinct grazing halo, which is seen as an area of cropped algae or bare rock around the sea urchin (Carpenter 1984, Verlaque 1984; Fig. 2A). These haloes are the result of sea urchin overgrazing macroalgae (i.e., urchin grazing rates exceeding algal growth). To establish the relationship between grazing impact and sea urchin size, we measured the diameter of haloes for 30 individual sea urchins ranging from 0.7 to $5.8 \mathrm{~cm}$ in test diameter. Given that preliminary observation of the results indicated a distinct threshold response to grazer impact, we fit a linear regression to all the points above $3 \mathrm{~cm}$ of test diameter, where the threshold point was evident based on the plotted data.

\section{Size-mediated predator non-consumptive effects}

We first used a series of controlled experiments in the laboratory to investigate how prey size mediates predator non-consumptive effects on sea urchin feeding behavior; we and then used a manipulative experiment in the field to test whether these effects flow through the food web to affect macroalgal assemblages under natural conditions (Fig. 1c).

TABLE 1. Final model summaries to test for differences in predation susceptability, halo length, urchin density, and the biomass of several algal groups, between high- and low-risk environments. The effect of sea urchin size was also tested for predation susceptibility and urchin density.

\begin{tabular}{|c|c|c|c|c|c|}
\hline Response variable and effect & Value & SD & $\mathrm{df}$ & $t$ & $P$ \\
\hline \multicolumn{6}{|l|}{ Predation } \\
\hline Size & -0.652 & 0.256 & 116 & -2.544 & 0.01 \\
\hline Risk & 1.728 & 1.537 & 116 & 1.124 & 0.26 \\
\hline Risk $\times$ Size & -0.016 & 0.393 & 116 & -0.04 & 0.97 \\
\hline \multicolumn{6}{|l|}{ Halo length } \\
\hline Risk & -1.783 & 0.175 & 1,28 & -10.10 & $<0.001$ \\
\hline \multicolumn{6}{|l|}{ Urchin density } \\
\hline Risk & -4.166 & 1.236 & 1,14 & -3.369 & $<0.01$ \\
\hline Size & -3.166 & 1.010 & 1,14 & -3.136 & $<0.01$ \\
\hline Risk $\times$ Size & 2.166 & 1.749 & 1,14 & 1.239 & 0.23 \\
\hline \multicolumn{6}{|l|}{ Algae biomass } \\
\hline \multicolumn{6}{|l|}{ Canopy } \\
\hline Risk & 1.270 & 0.715 & 1,25 & 1.775 & 0.008 \\
\hline \multicolumn{6}{|l|}{ Turf } \\
\hline Risk & 1.401 & 0.358 & 1,25 & 3.914 & $<0.001$ \\
\hline \multicolumn{6}{|l|}{ Codium } \\
\hline Risk & 0.562 & 0.630 & 1,25 & 0.892 & 0.380 \\
\hline \multicolumn{6}{|l|}{ Total } \\
\hline Risk & 1.309 & 0.307 & 1,25 & 4.257 & $<0.001$ \\
\hline
\end{tabular}

Notes: The terms retained in the final model, standard errors of these values, degrees of freedom, $t$ value, and $P$ value, are indicated. In all cases, the random effects were not significant and dropping them increased the model's AIC.

Bold values indicates significant of $P<0.05$ 

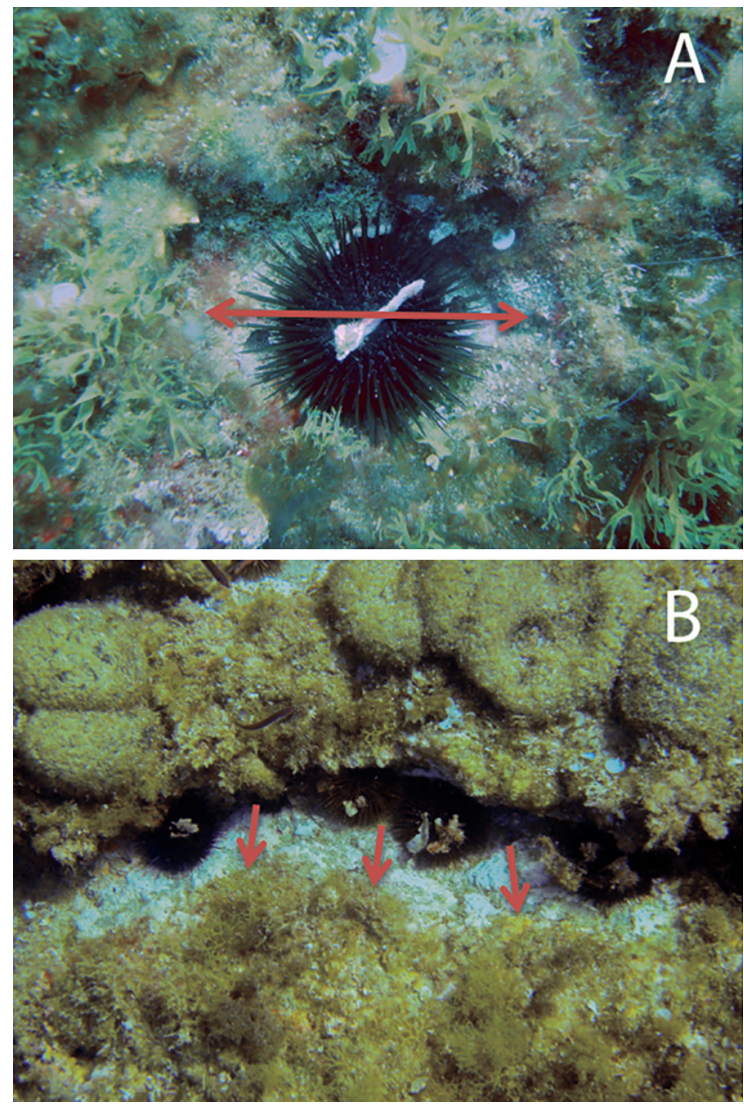

FIG. 2. Urchin grazing impact on macroalgal assemblage. (A) Individual sea urchin grazing halo. The red arrow represents the halo diameter. (B) Grazing halo in a crevice that includes several sea urchins. The red arrows represent the different measurements done along the crevice.

Laboratory experiments. - Sea urchins can evaluate predation risk using chemical cues from both injured conspecifics (the result of a predator attack) and the actual physical presence of predators (Morishita and Barreto 2011). To characterize size-mediated responses of sea urchins to cues from injured conspecifics, small (i.e., 2$3 \mathrm{~cm})$ and large $(4-5 \mathrm{~cm})$ Paracentrotus lividus individuals were collected from a cove near Blanes $\left(41^{\circ} 40^{\prime} 42^{\prime \prime} \mathrm{N}\right.$, $2^{\circ} 48^{\prime} 31^{\prime \prime}$ E) and maintained without food in large flowthrough aquaria for 1 and 2 weeks, respectively. Sea urchins were starved to ensure they all started with the same experimental conditions, since urchins that had fed shortly before collection in the field may have been less likely to feed again. Different starvation times were used as smaller urchins die of starvation earlier than larger ones (all authors, personal observation). The presence of feces in the large tanks confirmed that sea urchins had emptied their gut contents. In order to allow sea urchins of different sizes equal access to food resources, we used different sized tanks for the small and large sea urchin trials.

In the first trial, we placed large starved sea urchins in flow-through tanks $(15 \mathrm{~L})$ randomly allocated to "injured" and "control" trials $(n=8)$. Each tank was subdivided into three compartments, two containing a healthy sea urchin (two urchins per tank) and the last either with a wounded urchin (a small crack in the test, injured treatment) or left empty (control). In the second trial setup, we placed small starved sea urchins in 24 rectangular tanks ( $2 \mathrm{~L})$, subdivided into two compartments; one compartment always contained a healthy sea urchin and the other compartment contained either an injured urchin (injured treatment) or was left empty (control treatment; $n=12$ ). In both trials, experimental sea urchins were provided four $5 \times 1 \mathrm{~cm}$ pieces of the seagrass Posidonia oceanica (a common food for this species) that had been cleaned of epibionts. We used P. oceanica as a food resource since it is easy to control and measure in consumption experiments (Pagès et al. 2017), and the objective of this experiment was merely to confirm if predator nonconsumptive effects on prey feeding behavior existed. Leaves were removed after $7 \mathrm{~d}$, and the total area consumed was estimated using a ruler. Sea urchin grazing rates were then calculated for each tank by dividing consumption per urchin by elapsed days. Our tank set up used a flow-through system with the same source of water entering and exiting all tanks.

To validate whether sea urchins associate cues from injured conspecifics with the threat of predation, a separate experiment was conducted using sea urchins (only large sizes) and caged predators. Large adult sea urchins $(4-5 \mathrm{~cm})$ from the same cove near Blanes were collected and maintained in aquaria without food for 2 weeks. These individuals were then transferred to 10 replicate flow-through tanks (15 L), randomly assigned to predator $(n=5)$ and control trials $(n=5)$. In each of the predator tanks, we introduced a single predatory sea snail (Hexaplex trunculus, one of the main benthic predators of sea urchins; Sala and Zabala 1996, Boada et al. 2015), separated from the sea urchins with a plastic mesh. We used $H$. trunculus since it is easier to manipulate than other predators, and has previously been shown to negatively affect sea urchin performance (Pagès 2013). Sea snails could move freely inside the enclosures but could not access the rest of the tank where the sea urchin was placed. At the start of the trial, we provided sea urchins with four $5 \times 1 \mathrm{~cm}$ pieces of seagrass. After $7 \mathrm{~d}$, we quantified grazing rates following the procedure described above. During the course of the experiment, one predator escaped its tank and one sea urchin in the control treatment died. These two replicates were excluded from the analysis (final sample size for each treatment, $n=4$ ).

We analyzed differences in $P$. oceanica consumption rates between all treatments using linear models, with treatment (predator or injured sea urchin and control) as a fixed factor. The analysis was done independently for each size class of sea urchins (large and small sea urchins) because the initial conditions of the sea urchins and the set up of the experiments were different. In the first 
experiment with damaged conspecifics and large sea urchins, we additionally included tank as a random factor since the two sea urchins within each tank were not independent (Matassa 2010).

Field experiment. - To quantify whether the mechanisms identified in the laboratory had potential consequences for macroalgal assemblages in the field, we examined the grazing impact of sea urchins at our two contrasting predation risk zones (Fig. 1c). Instead of using cages to exclude predation on sea urchins, we introduced sea urchins in natural refugia (crevices) to restrict predators from consuming them. Sea urchin foraging excursions around these crevices create a conspicuous grazing halo around them (Fig. 2B; Nelson and Vance 1979, Verlaque 1984). The extent of this halo is a measure of how far from shelter herbivores are willing to risk foraging, and represents a rapid and effective way of measuring behaviorally mediated indirect effects of predators on vegetation (Madin et al. 2011). At high- and low-risk study sites, we identified a total of three large crevices $(>2 \mathrm{~m}$ long and $\sim 25 \mathrm{~cm}$ deep and wide; three crevices in the high-risk site; and two and one crevice in the low-risk sites, respectively) surrounded by macroalgae but devoid of sea urchins. We experimentally stocked the selected crevices with large sea urchins $(4.5-6 \mathrm{~cm} ; 11$ sea urchins per each meter of crevice length), as our field investigations determined that only large sea urchins modify their behavior when predators are present, and small-sized sea urchins do not overgraze macroalgae (see Results). We maintained sea urchin densities for 40 days. We then measured the extent of the halo (defined as the distance from the mouth of the crevice to the edge of the bare grazing patch, see Fig. 2B) at five random points around each crevice.

A linear mixed-effects model was used to test the effects of the fixed factor risk and the random factor crevice nested within risk (three levels) on the response variable halo length (five replicates/measurements per crevice). We did not include the factor site as a random factor because the total number of crevices was the same in the high- and the two low-risk sites $(n=3$; see experimental set up above).

\section{Influence of predator presence on sea urchin abundance and macroalgae}

To examine possible overall indirect effects of topdown control in the surveyed rocky reefs, we surveyed sea urchin density and algal assemblage cover and biomass at our high and low-risk sites (Fig. 1d). We measured sea urchin density by placing $40 \times 40 \mathrm{~cm}$ quadrats every $2 \mathrm{~m}$ along three $30-\mathrm{m}$ randomly placed transects ( 15 quadrats per transect, total $n=45$ per site) and classifying them into small and large classes, as per our laboratory experiments above (small, 1-3.9 cm; large, 4-6 cm; urchins smaller than $1 \mathrm{~cm}$ were not counted as they are highly inconspicuous). To obtain algal biomass estimates from each of the sites, algal biomass samples were additionally taken on each of the transects from a $20 \times 20 \mathrm{~cm}$ subquadrat on three randomly selected $40 \times 40 \mathrm{~cm}$ quadrats along the transect (total number of algal samples per site $=9$ ). All algae were scraped from the bottom using a putty knife and stored in a sealed bag filled with seawater. In the laboratory, algae were air-dried for $5 \mathrm{~min}$, weighed (fresh mass) and classified into functional groups (see below). Algae were then dried at $60^{\circ} \mathrm{C}$ for $48 \mathrm{~h}$, and reweighed (dry mass). For each $40 \times 40 \mathrm{~cm}$ quadrat, we also estimated the total cover for the following benthic components: canopy-forming algae $(>10 \mathrm{~cm}$ tall, e.g., Cystoseira spp., Dictyota spp., Sphaerococcus coronopifolius), algal turfs $(<10 \mathrm{~cm}$ tall; e.g., filamentous algae, Padina pavonica, Laurencia spp.), Codiums (Codium bursa and $C$. vermilara), crustose coralline algae (Mesophyllum spp., Litophyllum spp.), bare rock, and sediment.

We used generalized linear mixed-effects models to test the effect of risk on the response variables sea urchin density and algal biomass, with each algal class analyzed separately. We considered the factor site nested within risk (one and two sites in the high- and low-risk, respectively); and transect nested within site (three transects at each site), as random factors. In addition, we included sea urchin size class (two levels, large and small) as an additional explanatory fixed factor for the sea urchin density surveys.

\section{Results}

\section{Size-mediated predator consumptive effects}

Predation was size-dependent at all sites, decreasing as sea urchins increased with size (Table 1). No predation was recorded on sea urchins larger than $5.6 \mathrm{~cm}$. In the low predation risk scenario, the probability of a sea urchin being consumed rapidly decreased with size, with $20-30 \%$ average mortality for $2-3 \mathrm{~cm}$ sea urchins mortality (Fig. 3A; see also Appendix S1: Fig. S2 for site to site variation in predation susceptibility). Although predation was also clearly size dependent in the high-risk scenario, predation susceptibility decreased much less steeply with size, and $4-5 \mathrm{~cm}$ sea urchins still experienced $30-40 \%$ average mortality. Predation between the two risk levels differed the most in intermediate sea urchin sizes (Fig. 3A).

\section{Size-specific sea urchin grazing on algal assemblages}

Sea urchin size strongly affected their grazing impact (halo size) on algal cover, increasing non-linearly with size. Small size classes did not have noticeable effects on algal cover (i.e., they did not create a grazing halo; Fig. 3B), whilst sea urchin grazing impact increased linearly with sea urchin size for urchins larger than $3 \mathrm{~cm}$ $\left(R^{2}=0.698, P<0.001\right.$; Fig. 3B). 

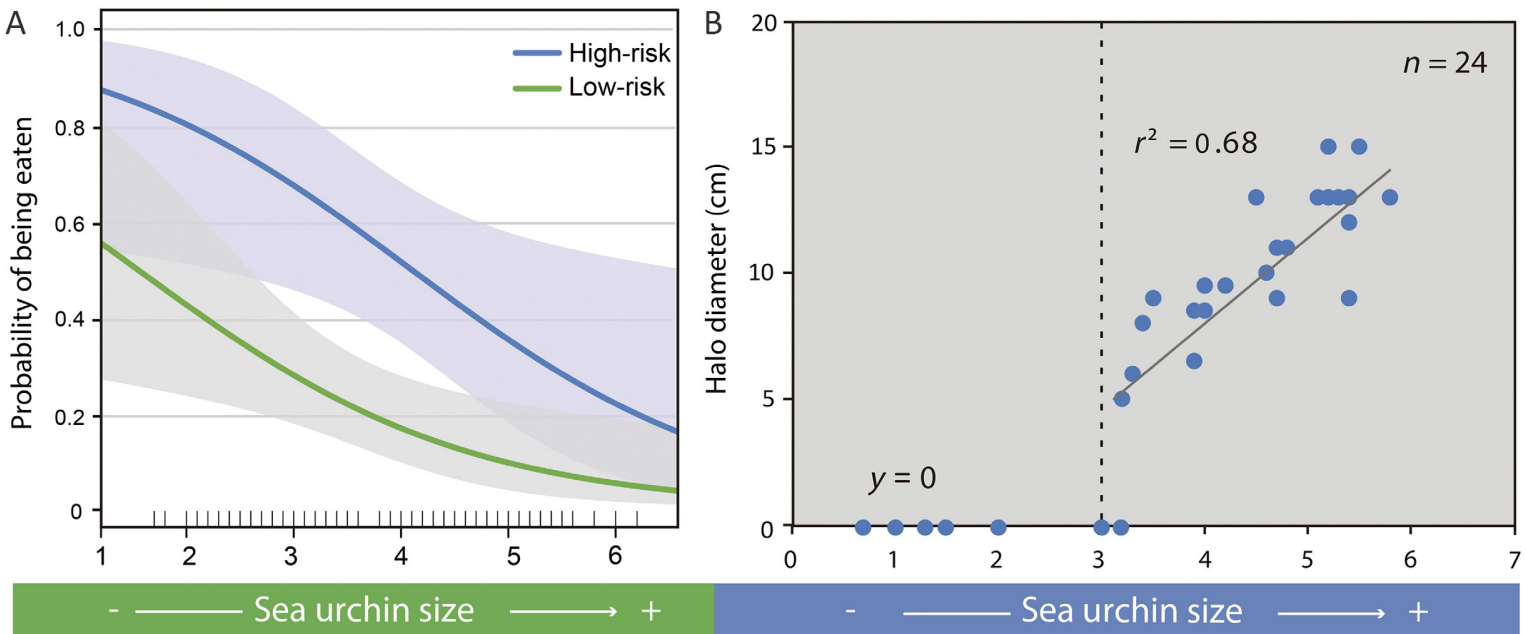

FIG. 3. (A) Urchin predation susceptibility in high and low predation risk areas (blue and green lines; inside and outside a marine reserve, respectively), and grazing impact (B) as a function of test diameter (cm). The predation susceptibility curves correspond to the predictions of a generalized linear model with a binomial distribution where a given sea urchin size has only two states (dead or alive), as per our field experiment results. The grazing impact increases linearly after a threshold of $3 \mathrm{~cm}$ (indicated by the dashed line), while the susceptibility of urchins to predation decreases with size.

\section{Size-mediated predator non-consumptive effects}

Laboratory experiments.-Small sea urchins did not alter their feeding rates significantly when injured conspecifics were present (Table 2; Fig. 4A). This was despite the fact that they were in smaller aquaria where injured conspecific cues were likely at higher concentrations (see Methods). In contrast, when we exposed large sea urchins to injured conspecifics, their mean grazing rates declined by $\sim 83 \%$ (Table 2; Fig. 4B). Similarly, the presence of predator cues suppressed large sea urchin grazing by $\sim 96 \%$ on average (Table 2 ; Fig. $4 \mathrm{C}$ ).

Field experiment.-A clear grazing halo had developed around the crevices experimentally stocked with sea urchins after 40 days. In the high risk-area, the grazing impact of sea urchins around the crevices was significantly lower than in the low-risk area (Table 1; Fig. 5A), featuring halos $60 \%$ smaller on average (high-risk halo length, $8.5 \pm 1.8 \mathrm{~cm}$; low-risk halo length, $20.3 \pm 3.2 \mathrm{~cm}$; mean $\pm \mathrm{SE}$ ).

TABLE 2. Generalized linear model results to test for differences in Posidonia oceanica consumption rates between a fear treatment (injured conspecific or predator odor) and a control in different urchin sizes (small or large).

\begin{tabular}{llcl}
\hline \hline Experiment & $\mathrm{df}$ & $F$ & $P$ \\
\hline Injured conspecific & & 1.21 & 0.28 \\
$\quad$ Small & 1,22 & 19.98 & $\mathbf{0 . 0 0 4}$ \\
$\quad$ Large & 1,6 & & \\
$\begin{array}{l}\text { Predator odor } \\
\quad \text { Large }\end{array}$ & 1,6 & 19.37 & $\mathbf{0 . 0 0 4}$ \\
\hline
\end{tabular}

Bold values indicates Significant of $P<0.05$

\section{Influence of predator presence on sea urchin abundance and macroalgae}

Mean sea urchin density was significantly lower at the high-risk site compared to the low-risk sites (Table 1), representing a more than twofold difference of both small and large sea urchin size classes (Table 1, Fig. 5B; see also Appendix S1: Fig. S3 for site to site variation in sea urchin density). Overall, total algal biomass was lower at low-risk sites, as was the biomass of canopy-forming algae and algal turfs (Table 1, Fig. 5C, Appendix S1: Fig. S4). In contrast, the biomass of Codium species, an alga that is usually avoided by sea urchins, was not significantly different between locations. These trends were similar when considering percentage cover (Appendix S1: Fig. S5). The percentage of bare rock cover was also higher at low-risk sites (Appendix S1: Fig. S5).

\section{Discussion}

Our results provide further evidence of the existence of non-consumptive trophic cascades in subtidal marine systems (e.g. Byrnes et al. 2006, Haggerty et al. 2018), but suggest that prey body size plays a key role in determining their strength and impacts on ecosystem structure, as the relative importance of consumptive and nonconsumptive effects varied with the ontogeny of prey (Fig. 6B). Consumptive effects were strongest on small prey and decreased with size as sea urchins become increasingly difficult to capture and kill (Sinclair et al. 2003), with the oldest and largest individuals being virtually beyond the reach of most extant predators. 


\section{Injured conspecific cues}

A

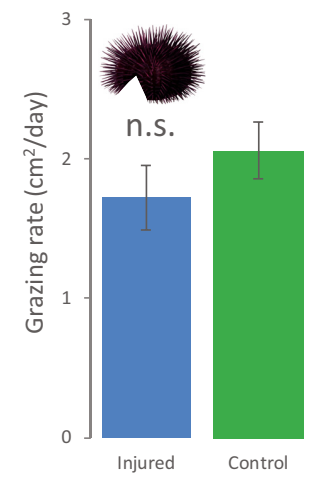

B

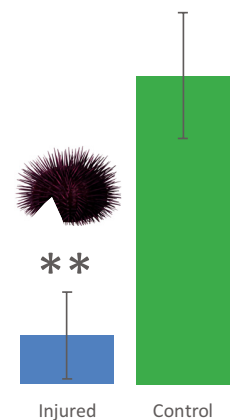

C

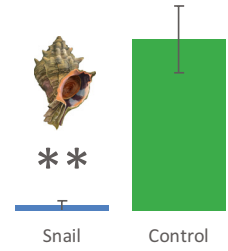

Small urchins

Large urchins

FIG. 4. Urchin responses to predation risk cues in the laboratory. (A) Grazing rates (mean \pm SE) of small (2-3 cm) urchins did not differ with and without exposure to injured conspecific cues. Grazing rates of large $(4-5 \mathrm{~cm})$ urchins decreased when exposed to cues from injured conspecifics (B; illustrated by the cracked urchin) and (C) predator cues (sea snail). Grazing rates between size classes are not comparable as the experiments were performed in different conditions (see Methods). Asterisks denote significant differences $(* * P<0.01)$, n.s. denotes no significant differences between treatments.

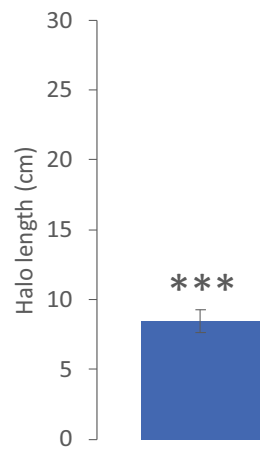

High-risk

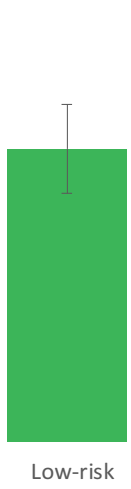

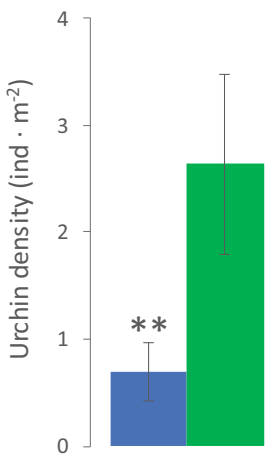

Small

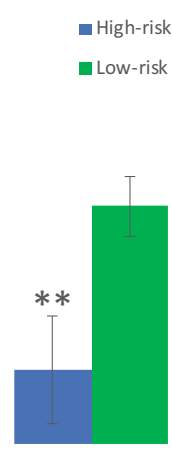

Large

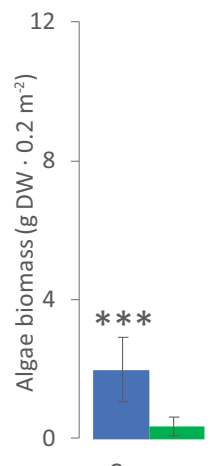

Canopy

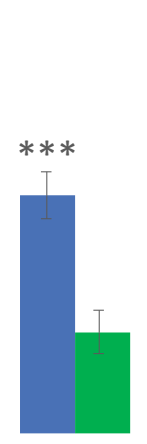

Turf

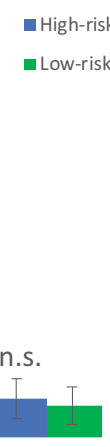

Codium

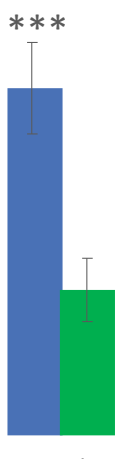

Total

FIG. 5. (A) Measured halo length (grazing impact) in the sea urchin stocking experiment between high and low predation risk scenarios. (B) Density of sea urchins (small and large classes; 1-3 cm and 3.1-6 cm test diameter, respectively) in areas with high and low predation risk. (C) Biomass of different categories of macroalgae in areas with high and low predation risk. Values are means \pm SE. Asterisks denote significant differences $\left({ }^{* *} P<0.01,{ }^{* *} P<0.001\right)$, n.s. denotes no significant differences between treatments.

However, with size, prey also grew in fear, reducing their herbivory in the presence of predators, even when predation posed a comparatively small threat (Fig. 6A). This ontogenetic decoupling between risk and fear has farreaching consequences when prey are key structuring ecosystem agents, whose grazing impacts also vary strongly with age and size. Thus, while predators play a strong role in maintaining the population of smaller prey, their ability to mediate the behavior of larger individuals merely with their presence makes them doubly effective agents of top-down control (Fig. 6, dashed arrow).
Size-dependent predation can be a primary organizing force in ecological communities (Brooks and Dodson 1965, Sousa 1993, Vadas et al. 1994), with sizes that escape predation being able to perform critical ecosystem functions (Paine 1976). Urchin body size was strongly correlated with predation susceptibility, suggesting that fish predators strongly influence the size structure of key herbivorous prey in our system, as well as their ecological function. Although our tethering assays may have overestimated the predation rates of small individuals in natural field conditions by restricting their ability to find refugia, predation is still heavily size 

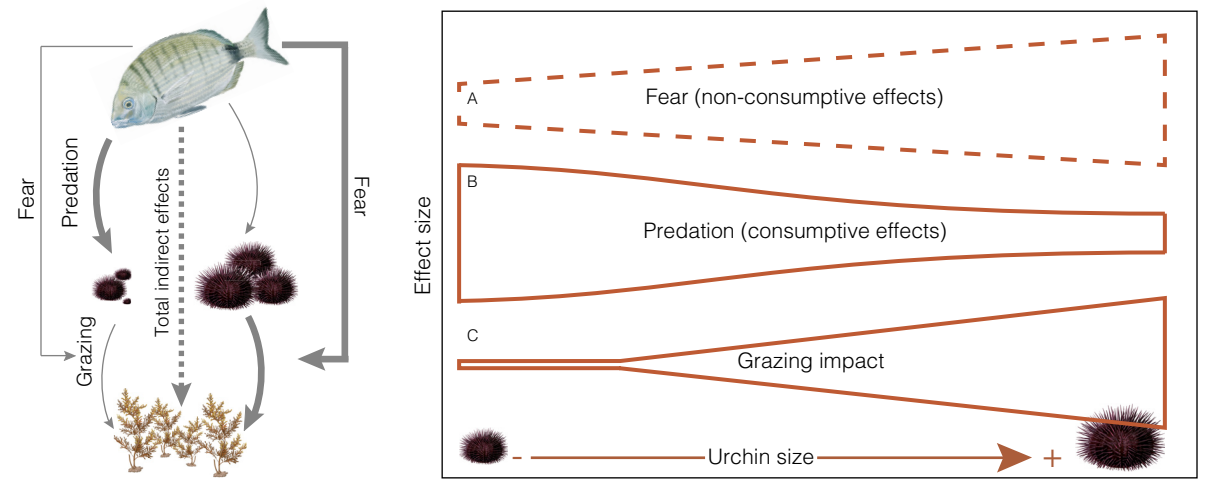

FIG. 6. Schematic representation of the effects of sea urchin (Paracentrotus lividus) size-specific trophic interactions in the Mediterranean Sea. The overall indirect positive effect (gray dashed line) of predators on macroalgae is a combination of non-consumptive and consumptive effects. (A) Predator presence affects the grazing behavior of large sea urchins (non-consumptive effect), but not smaller urchins - although urchin responses along the entire size spectrum were not evaluated in our assays (indicated by the dashed brown lines). (B) Predation decreases with sea urchin size being greatest on small individuals (consumptive effect). (C) Grazing impact (i.e., halo size), increased non-linearly with size, with only urchins larger $>3 \mathrm{~cm}$ capable of creating patches of bare rock.

dependent even when urchins have access to shelters (Guidetti 2007). That is because while young prey are easy pickings for a diverse guild of fishes (Sala 1997), large sea urchins are able to reach a size refuge, with only a predator individuals from a handful of species having the necessary strength to crack their tests and negotiate their spines (Sala et al. 1998, Hereu et al. 2013, Stevenson et al. 2016). In systems with a wide range of predators and predator functional traits (e.g., hunting mode, mobility) however, escaping from one predator may not guarantee safety. For example, large adult sea urchins reach a size refuge by sea stars (Burt et al. 2018), but are preferred and actively targeted by sea otters (Stevenson et al. 2016). The abundance and type of predators in a given habitat will thus influence the risk profile of each ontogenetic stage of prey, as well as their net contribution to ecosystem function.

Sea urchins could detect predation risk via the cues released by predators or injured conspecifics in our laboratory experiments, suggesting a chemosensory mechanism geared to respond to fear. Chemical cues have been shown to trigger different behavioral responses in several species of sea urchin (Vadas and Elner 2003, Freeman 2006, Matassa 2010, Morishita and Barreto 2011), and seem to play a key role in subtidal ecosystems where invertebrates are important grazers (Haggerty et al. 2018). An important consideration when assessing the effects of fear on prey populations using predator cues is that the magnitude of those cues may be artificially enhanced by the experimental setup, making them difficult to compare with cues in the prey's natural environment (Peers et al. 2018). Turbulent, high-flow conditions may rapidly dilute predator cues in aquatic environments, with prey showing low response levels to predator presence in field conditions compared to laboratory trials (Freeman 2006, McKay and Heck 2008, Harding and Scheibling 2015). Crucially however, the reduced grazing haloes we recorded in high-risk environments show that prey responses in the presence of predators were not merely a laboratory artefact, but had measurable functional consequences in natural field conditions.

Interestingly, large sea urchins showed marked behavioral responses to the presence of predators, while smaller urchins, despite being more vulnerable to predation, did not. The asset protection principle (Clark 1994) offers a potential explanation for the observed muted responses of small prey to predator cues. Small sea urchins may have fewer assets to protect (e.g., lower reproductive potential; Sánchez-España et al. 2004), and may be bolder and forage in risky situations since they have more to gain from each foraging event. Metabolic theory states that small organisms have higher energy intake requirements per unit weight than large ones (Hemmingsen 1960), and small sea urchins indeed consume algae at higher mass-specific rates compared to larger urchins (Stevenson et al. 2016). Therefore, smaller prey may also tolerate higher risks since they are much more vulnerable to starvation (McNamara and Houston 1987). On the other hand, large individuals may be able to afford missing foraging excursions since they can survive on their reserves for longer and be less willing to jeopardize their survival given their higher reproductive potential. Whether the response threshold to predator cues varies with sea urchin size (i.e., smaller urchins responding to concentrations of predator/conspecific cues higher than the ones used in our study) remains to be tested. Alternatively, it could also be possible that smaller sea urchins are incapable of responding to predator presence, or that fear is an "acquired" behavior that develops with age. If fear is an acquired behavior, it is possible that growing up in predator-rich environments conditions prey to reduce their foraging in the presence of these cues.

The reduction of predation risk as prey increased with size was matched with a concomitant increase in their 
functional impact on the ecosystem. Unregulated, sea urchin populations have driven dramatic regime shifts of several temperate reefs worldwide (including the Mediterranean), as they destructively overgraze macroalgal forests transforming them into rocky barrens (Pinnegar et al. 2000, Filbee-Dexter and Scheibling 2014, Ling et al. 2015, Boada et al. 2017). Our field observations reveal that the vast bulk of overgrazing is probably mainly due to large individuals ( $>3 \mathrm{~cm}$ in test diameter), whose grazing rates were able to surpass algal growth, thus creating patches of bare rock known as grazing halos. Although mass-specific consumption rates decrease with animal biomass (size), our findings indicate that the absolute consumption rates of herbivores, which, contrastingly, increase with body size, are, key drivers of ecosystem structure (Lokrantz et al. 2008, Fong et al. 2016).

Functionally then, the foraging behavior of larger herbivorous prey is key (Bakker et al. 2015), and the ability of predators to disproportionately influence their behavior makes non-consumptive pathways critical in maintaining trophic cascades (Fig. 6). Supply-side processes and direct predatory control of younger individuals certainly remain the primary filters limiting how many individuals make it to adult size classes (Prado et al. 2012), but in areas with plenty of physical refuge, prey may be able to effectively negotiate this bottleneck by limiting their foraging and their movement until they are large enough to escape predation risk (Sala et al. 1998, Boada et al. 2015). Under these conditions, non-consumptive predator control of prey in late ontogenetic stages may be essential in preventing regime shifts, particularly in systems where inherent conditions lower the resilience of the vegetated state (Boada et al. 2017).

Going forward, it would be important to determine how common the decoupling between predator effects and prey ontogeny is in other predator-prey systems. Predator functional characteristics such as hunting mode have a strong influence on the relative importance of their effects on prey as they shift ontogenetic stages (Preisser et al. 2007, Burt et al. 2018). For instance, size-limited predation and a weakening of predator consumptive effects with increasing prey size often occurs when predators are physically constrained in their ability to capture prey (e.g., by the size of their gape; Urban 2007), as is common in aquatic environments (Brose et al. 2006). However, some predators may overcome these constraints with hunting tools (e.g., claws, radulae, fangs), which enable them to capture much larger prey than their size would normally allow (Brose et al. 2006). On the other hand, the imprint of fear will depend largely on the ability of prey to accurately evaluate risk in relation to their ontogenetic stage. Apart from having the neurosensory mechanisms of detecting danger and/or the ability to learn from early experience, dynamic risk evaluation requires additional sophistication in accounting for your own size, physical state, and defensive capabilities in relation to the predators around (Vadas et al. 1994).
In summary, the decoupling between risk and fear as prey grow documented here suggests that the imprint of fear may have important consequences for ecosystem functioning even after prey reach an apparent refuge size from predation. Its ecological significance will likely be highest when (1) there are size-specific asymmetries in predator effects due to trade-offs (e.g., when larger prey may be less at risk of predation, but have more assets to protect, making them more fearful) and (2) prey that reach an escape size perform critical ecosystem functions. Identifying how common, and under what circumstances these conditions are met would help clarify how important these ontogenetic switches in predator-prey interactions are to the structuring of terrestrial and aquatic ecosystems. That predator non-consumptive effects are prevalent across ecosystems is already clear (Peacor and Werner 2004, Schmitz et al. 2004, Trussell et al. 2006, Burkholder et al. 2013), even in the most paradigmatic examples of trophic cascades (Peckarsky et al. 2008). A fuller understanding of how such non-consumptive effects vary with life stage will significantly enrich predatorprey theory (Preisser and Bolnick 2008). As we show, fear can cast a long shadow, continuing to influence prey behavior and function long after the risk has passed.

\section{Acknowledgments}

The authors would like to thank Manel Bolivar and Xavier Buñuel for field support, Sandra Muñoz for contributing significantly to the laboratory experiments, and Toni Llobet for the illustrations in Figs. 3 and 5. 1,4 and 6. The Spanish Ministry of Science and Innovation funded this research (UMBRAL; Respuestas de la vegetación marina bentónica al estrés: transiciones críticas, resiliencia y oportunidades de gestión', CTM2017-86695-C3-3-R) and supported J. Boada's scholarship (no. BES-2011-043630). The Spanish National Research Council supported R. Arthur's visitorship with the Memorandum of Understanding between CEAB-IMEDEA-NCF. J. Boada acknowledges the funding received by the Australian Government (ERF_PDR_5888_2017). J. F. Pagès acknowledges financial support from the Welsh Government and Higher Education Funding Council for Wales through the Sêr Cymru National Research Network for Low Carbon, Energy and Environment.

\section{Literature Cited}

Atwood, T. B., R. M. Connolly, E. G. Ritchie, C. E. Lovelock, M. R. Heithaus, G. C. Hays, J. W. Fourqurean, and P. I. Macreadie. 2015. Predators help protect carbon stocks in blue carbon ecosystems. Nature Climate Change 5:1038-1045.

Bakker, E. S., J. F. Pagès, R. Arthur, and T. Alcoverro. 2015. Assessing the role of large herbivores in the structuring and functioning of freshwater and marine angiosperm ecosystems. Ecography 38:1-18.

Boada, J., R. Arthur, S. Farina, Y. Santana, O. Mascaró, J. Romero, and T. Alcoverro. 2015. Hotspots of predation persist outside marine reserves in the historically fished Mediterranean Sea. Biological Conservation 191:67-74.

Boada, J., R. Arthur, D. Alonso, J. F. Pagès, A. Pessarrodona, S. Oliva, G. Ceccherelli, L. Piazzi, J. Romero, and T. Alcoverro. 2017. Immanent conditions determine imminent collapses: 
nutrient regimes define the resilience of macroalgal communities. Proceedings of the Royal Society B 284:20162814.

Breheny, P., and W. Burchett. 2017. visreg: Visualization of Regression Models. R package version 2.4-1. https://CRAN. $\mathrm{R}$-project.org/package $=$ visreg.

Brooks, J. L., and S. I. Dodson. 1965. Predation, body size, and composition of plankton. Science 150:28-35.

Brose, U., et al. 2006. Consumer-resource body-size relationships in natural foodwebs. Ecology 87:2411-2417.

Burkholder, D. A., M. R. Heithaus, J. W. Fourqurean, A. J. Wirsing, and L. M. Dill. 2013. Patterns of top-down control in a seagrass ecosystem: Could a roving apex predator induce a behaviour-mediated trophic cascade? Journal of Animal Ecology 82:1192-1202.

Burt, J. M., M. T. Tinker, D. K. Okamoto, K. W. Demes, K. Holmes, and A. K. Salomon. 2018. Sudden collapse of a mesopredator reveals its complementary role in mediating rocky reef regime shifts. Proceedings of the Royal Society B 285:20180553.

Byrnes, J., J. J. Stachowicz, K. M. Hultgren, A. R. Hughes, S. V. Olyarnik, and C. S. Thornbert. 2006. Predator diversity strengthens trophic cascades in kelp forests by modifying herbivore behaviour. Ecology Letters 9:61-71.

Cardona, L., J. Moranta, O. Reñones, and B. Hereu. 2013. Pulses of phytoplanktonic productivity may enhance sea urchin abundance and induce state shifts in Mediterranean rocky reefs. Estuarine, Coastal and Shelf Science 133:88-96.

Carpenter, R. C. 1984. Predator and population density control of homing behavior in the Caribbean echnoid Diadema antillarum. Marine Biology 108:101-108.

Carr, M., and D. Reed. 2016. Shallow rocky reefs and kelp forests. Pages 311-336 in H. Mooney, and E. Zavaleta, editors. Ecosystems of California. University of California Press, Berkeley, California, USA.

Catano, L. B., M. C. Rojas, R. J. Malossi, J. R. Peters, M. R. Heithaus, J. W. Fourqurean, and D. E. Burkepile. 2016. Reefscapes of fear: predation risk and reef hetero-geneity interact to shape herbivore foraging behaviour. Journal of Animal Ecology 85:146-156.

Clark, C. W. 1994. Antipredator behavior and the asset-protection principle. Behavioral Ecology 5:159-170.

Cowen, R. K. 1983. The effect of sheephead (Semicossyphus pulcher) predation on red sea urchin (Strongylocentrotus franciscanus) populations: an experimental analysis. Oecologia 58:249-255.

Eklöv, P., and E. E. Werner. 2000. Multiple predator effects on size-dependent behavior and mortality of two species of anuran larvae. Oikos 88:250-258.

Estes, J. A., and D. O. Duggins. 1995. Sea otters and kelp forests in Alaska: generality and variation in a community ecological paradigm. Ecological Monographs 65:75-100.

Estes, J. A., et al. 2014. Trophic downgrading of Planet Earth. Science 333:301-306.

Filbee-Dexter, K., and R. E. Scheibling. 2014. Sea urchin barrens as alternative stable states of collapsed kelp ecosystems. Marine Ecology Progress Series 495:1-25.

Fong, P., N. M. Frazier, C. Tompkins-Cook, R. Muthukrishnan, and C. R. Fong. 2016. Size matters: experimental partitioning of the strength of fish herbivory on a fringing coral reef in Moorea, French Polynesia. Marine Ecology 37:933942.

Freeman, A. 2006. Size-dependent trait-mediated indirect interactions among sea urchin herbivores. Behavioral Ecology 17:182-187.

García-Rubies, A., B. Hereu, and M. Zabala. 2013. Long-term recovery patterns and limited spillover of large predatory fish in a Mediterranean MPA. PLoS ONE 8:e73922.
Guidetti, P. 2007. Predator diversity and density affect levels of predation upon strongly interactive species in temperate rocky reefs. Oecologia 154:513-520.

Guidetti, P., et al. 2014. Large-scale assessment of Mediterranean marine protected areas effects on fish assemblages. PLoS ONE 9:e91841.

Haggerty, M. B., T. W. Anderson, and J. D. Long. 2018. Fish predators reduce kelp frond loss via a trait-mediated trophic cascade. Ecology 99:1574-1583.

Harding, A. P. C., and R. E. Scheibling. 2015. Feed or flee: effect of a predation-risk cue on sea urchin foraging activity. Journal of Experimental Marine Biology and Ecology 466:59-69.

Harrold, C., and D. C. Reed. 1985. Food availability, sea urchin grazing, and kelp forest community structure. Ecology 66:1160-1169.

Hemmingsen, A. M. 1960. Energy metabolism as related to body size and respiratory surfaces, and its evolution. Niels Steensens Hospital, Copenhagen, Denmark.

Hereu, B. 2004. The role of trophic interactions between fishes, sea urchins and algae in the northwest Mediterranean rocky infralittoral. University of Barcelona, Barcelona, Spain.

Hereu, B. 2005. Movement patterns of the sea urchin Paracentrotus lividus in a marine reserve and an unprotected area in the NW Mediterranean. Marine Ecology 26:54-62.

Hereu, B., M. Zabala, and E. Sala. 2008. Multiple controls of community structure and dynamics in a sublittoral marine environment. Ecology 89:3423-3435.

Hereu, B., C. Linares, A. M. Ricart, À. Rodríguez, E. Aspillaga, D. Díaz, L. Navarro, and J. L. Riera. 2012. Cartography of the habitats of the Mongrí Coast and Medes Islands (in Catalan). Cartografia bionòmica dels hàbitats de la costa del Montgrí i les illes Medes. Pages 35-62 in B. Hereu, and X. Quintana, editors. El fons marí de les illes Medes i el Montgrí: quatre dècades de recerca per a la conservació. Càtedra d'Ecosistemes Litorals Mediterranis, Girona, Spain.

Hereu, B., M. Zabala, and E. Sala. 2013. Multiple controls of community structure and dynamics in a sublittoral marine environment. Ecology 89:3423-3435.

Krenek, L., and V. H. W. Rudolf. 2014. Allometric scaling of indirect effects: body size ratios predict non-consumptive effects in multi-predator systems. Journal of Animal Ecology 83:1461-1468

Lima, S. L., and T. J. Valone. 1986. Influence of predation risk on diet selection: a simple example in the grey squirrel. Animal Behaviour 34:536-544.

Ling, S., C. R. Johnson, S. D. Frusher, and K. R. Ridgway. 2009. Overfishing reduces resilience of kelp beds to climatedriven catastrophic phase shift. Proceedings of the National Academy of Sciences USA 106:22341-22345.

Ling, S., et al. 2015. Global regime shift dynamics of catastrophic sea urchin overgrazing. Philosophical Transactions of the Royal Society B 370:20130269.

Llompart, C., and L. Pallí. 1984. Geology of the Medes Islands (in Catalan). Pages 61-74 in J. Ros, I. Olivella, and J. M. Gili, editors. The natural systems of the Medes Islands. Els sistemes naturals de les illes Medes. Institut d'Estudis Catalans, Barcelona, Spain.

Lokrantz, J., M. Nyström, M. Thyresson, and C. Johansson. 2008. The non-linear relationship between body size and function in parrotfishes. Coral Reefs 27:967-974.

Madin, E. M. P., J. S. Madin, and D. J. Booth. 2011. Landscape of fear visible from space. Scientific Reports 1:14.

Matassa, C. M. 2010. Purple sea urchins Strongylocentrotus purpuratus reduce grazing rates in response to risk cues from the spiny lobster Panulirus interruptus. Marine Ecology Progress Series 400:283-288. 
McKay, K., and K. L. Heck Jr. 2008. Presence of the Jonah crab Cancer borealis significantly reduces kelp consumption by the green sea urchin Strongylocentrotus droebachiensis. Marine Ecology Progress Series 356:295-298.

McNamara, J. M., and A. I. Houston. 1987. Starvation and predation as factors limiting population size. Ecology 68:1515-1519

Montgrí Medes Islands and Baix Ter Natural Park. 2010. Regulations and advice for marine activities. Government of Catalonia, Barcelona, Spain.

Morishita, V. R., and R. E. Barreto. 2011. Black sea urchins evaluate predation risk using chemical signals from a predator and injured con- and heterospecific prey. Marine Ecology Progress Series 435:173-181.

Nelson, B. V., and R. R. Vance. 1979. Diel foraging patterns of the sea urchin Centrostephanus coronatus as a predator avoidance strategy. Marine Biology 51:251-258.

Orrock, J. L., E. L. Preisser, J. H. Grabowski, and G. C. Trussell. 2013. The cost of safety: refuges increase the impact of predation risk in aquatic systems. Ecology 94:573-579.

Pagès, J. F. 2013. A behavioural seascape ecology approach to macrophyte herbivory. University of Barcelona, Barcelona, Spain.

Pagès, J. F., T. M. Smith, F. Tomas, N. Sanmartí, J. Boada, H. De Bari, M. Pérez, J. Romero, R. Arthur, and T. Alcoverro. 2017. Contrasting effects of ocean warming on different components of plant-herbivore interactions. Marine Pollution Bulletin 134:55-65.

Paine, R. T. 1976. Size-limited predation: an observational and experimental approach with the Mytilus-Pisaster interaction. Ecology 57:858-873.

Patton, M. Q. 1999. Enhancing the quality and credibility of qualitative analysis. Health Services Research 34:1189-1208.

Peacor, S. D., and E. E. Werner. 2001. The contribution of traitmediated indirect effects to the net effects of a predator. Proceedings of the National Academy of Sciences USA 98:3904-3908.

Peacor, S. D., and E. E. Werner. 2004. How dependent are species-pair interaction strengths on other species in the food web? Ecology 85:2754-2763.

Peckarsky, B. L., et al. 2008. Revisiting the classics: considering nonconsumptive effects in textbook examples of predatorprey interactions. Ecology 89:2416-2425.

Peers, M. J. L., et al. 2018. Quantifying fear effects on prey demography in nature. Ecology 99:1716-1723.

Pinnegar, J. K., et al. 2000. Trophic cascades in benthic marine ecosystems: lessons for fisheries and protected-area management. Environmental Conservation 27:179-200.

Prado, P., F. Tomas, S. Pinna, S. Farina, G. Roca, G. Ceccherelli, J. Romero, and T. Alcoverro. 2012. Habitat and scale shape the demographic fate of the keystone sea urchin Paracentrotus lividus in Mediterranean macrophyte communities. PLoS ONE 7:e35170.

Preisser, E. L., and D. I. Bolnick. 2008. The many faces of fear: comparing the pathways and impacts of nonconsumptive predator effects on prey populations. PLoS ONE 3:e2465.

Preisser, E. L., and J. L. Orrock. 2012. The allometry of fear: interspecific relationships between body size and response to predation risk. Ecosphere 3:77.

Preisser, E. L., J. L. Orrock, and O. J. Schmitz. 2007. Predator hunting mode and habitat domain alter nonconsumptive effects in predator-prey interactions. Ecology 88:2744-2751.

R Development Core Team. 2016. R: a language and environment for statistical computing. R Foundation for Statistical Computing, Vienna, Austria. http://www.R-project.org

Rasher, D. B., A. S. Hoey, and M. E. Hay. 2017. Cascading predator effects in a coral reef ecosystem. Scientific Reports $7: 1-10$.
Sala, E. 1997. Fish predators and scavengers of the sea urchin Paracentrotus lividus in protected areas of the north-west Mediterranean Sea. Marine Biology 129:531-539.

Sala, E., and M. Zabala. 1996. Fish predation and the structure of the sea urchin Paracentrotus lividus populations in the NW Mediterranean. Marine Ecology Progress Series 140:71-81.

Sala, E., C. F. Boudouresque, and M. Harmelin-Vivien. 1998. Fishing, trophic cascades, and the structure of algal assemblages: evaluation of an old but untested paradigm. Oikos $82 \cdot 425-439$

Sala, E., et al. 2012. The structure of Mediterranean rocky reef ecosystems across environmental and human gradients, and conservation implications. PLoS ONE 7:e32742.

Sánchez-España, A. I., I. Martínez-Pita, and F. J. García. 2004. Gonadal growth and reproduction in the commercial sea urchin Paracentrotus lividus (Lamarck, 1816) (Echinodermata: Echinoidea) from southern Spain. Hydrobiologia 519:61-72.

Scheibling, R. E., and J. Hamm. 1991. Interactions between sea urchins (Strongylocentrotus droebachiensis) and their predators in field and laboratory experiments. Marine Biology 110:105-116.

Schmitz, O. J., A. P. Beckerman, K. M. O'Brien, K. M. O. Brien, and N. Haven. 1997. Behaviorally mediated trophic cascades: effects of predation risk on food web interactions. Ecology 78:1388-1399.

Schmitz, O. J., V. Krivan, and O. Ovadia. 2004. Trophic cascades: the primacy of trait-mediated indirect interactions. Ecology Letters 7:153-163.

Schmitz, O. J., J. H. Grabowski, B. L. Peckarsky, E. L. Preisser, G. C. Trussell, and J. R. Vonesh. 2008. From individuals to ecosystem function: toward an integration of evolutionary and ecosystem ecology. Ecology 89:2436-2445.

Shears, N. T., and R. C. Babcock. 2003. Continuing trophic cascade effects after 25 years of no-take marine reserve protection. Marine Ecology Progress Series 246:1-16.

Shurin, J. B., E. T. Borer, E. W. Seabloom, K. Anderson, C. A. Blanchette, B. R. Broitman, S. D. Cooper, and B. S. Halpern. 2002. A cross-ecosystem comparison of the strength of trophic cascades. Ecology Letters 5:785-791.

Sinclair, A. R. E., S. Mduma, and J. S. Brashares. 2003. Patterns of predation in a diverse predator-prey system. Nature 425:288-290.

Sousa, W. P. 1993. Size-dependent predation on the salt-marsh snail Cerithidea californica Haldeman. Journal of Experimental Marine Biology and Ecology 166:19-37.

Spyksma, A. J. P., R. B. Taylor, and N. T. Shears. 2017. Predation cues rather than resource availability promote cryptic behaviour in a habitat-forming sea urchin. Oecologia 183:821-829.

Stevenson, C. F., K. W. Demes, and A. K. Salomon. 2016. Accounting for size-specific predation improves our ability to predict the strength of a trophic cascade. Ecology and Evolution 6:1041-1053.

Suraci, J. P., M. Clinchy, L. M. Dill, D. Roberts, and L. Y. Zanette. 2016. Fear of large carnivores causes a trophic cascade. Nature Communications 7:10698.

Trussell, G. C., P. J. Ewanchuk, and C. M. Matassa. 2006. Habitat effects on the relative importance of trait- and densitymediated indirect interactions. Ecology Letters 9:1245-1252.

Urban, M. C. 2007. The growth-predation risk trade-off under a growing gape-limited predation threat. Ecology 88:25872597.

Vadas, R. L., and R. W. Elner. 2003. Responses to predation cues and food in two species of sympatric, tropical sea urchins. Marine Ecology 24:101-121.

Vadas, R. L., M. T. Burrows, and R. N. Hughes. 1994. Foraging strategies of dogwhelks, Nucella lapillus (L.): interacting 
effects of age, diet and chemical cues to the threat of predation. Oecologia 100:439-450.

Verlaque, M. 1984. Biologie des juvéniles de l'oursin herbivore Paracentrotus lividus (Lamarck): séléctivité du broutage et impact de l'espèce sur les communautés algales de substrat rocheaux en Corse (Méditerranée, France). Botanica Marina 27:401-424.

Werner, E. E., and J. F. Gilliam. 1984. The ontogenetic niche and species interactions in size-structured populations. Annual Review of Ecology and Systematics 15:393-425.
Werner, E. E., J. F. Gilliam, D. J. Hall, and G. G. Mittelbach. 1983. An experimental test of the effects of predation risk on habitat use in fish. Ecology 64:1540-1548.

Wirsing, A. J., M. R. Heithaus, and L. M. Dill. 2007. Can you dig it? Use of excavation, a risky foraging tactic, by dugongs is sensitive to predation danger. Animal Behaviour 74:10851091.

Zuur, A. F., E. N. Leno, N. J. Walker, A. A. Saveliev, and G. M. Smith. 2011. Mixed effects models and extensions in ecology with R. Page Public Health. Springer-Verlag. New York, USA.

\section{SUPPORTING INFORMATION}

Additional supporting information may be found in the online version of this article at http://onlinelibrary.wiley.com/doi/ 10.1002/ecy.2649/suppinfo 